\title{
Thoron emanation and exhalation of Slovenian soils determined by a PIC detector-equipped radon monitor
}

\author{
Jácint Jónás, \\ Zoltán Sas, \\ Janja Vaupotic, \\ Erika Kocsis, \\ János Somlai, \\ Tibor Kovács
}

\begin{abstract}
The health risk from thoron (Rn-220) is usually ignored owing to its short half-life (55.6 s), but the generated thoron decay products can cause a significant dose contribution. In this study, altogether 51 Slovenian soil samples were investigated using an accumulation chamber technique to obtain information about thoron exhalation features. The obtained (massic) thoron exhalation results varied between 6.9 and $149 \mathrm{mBq} \cdot \mathrm{kg}^{-1} \cdot \mathrm{s}^{-1}$ (average: $55.2 \mathrm{mBq} \cdot \mathrm{kg}^{-1} \cdot \mathrm{s}^{-1}$ ). The Th-232 content was determined using HPGe gamma spectrometry. The Th-232 activity concentration ranged between 9.3 and $161.7 \mathrm{~Bq} \cdot \mathrm{kg}^{-1}$ (average: $64.6 \mathrm{~Bq} \cdot \mathrm{kg}^{-1}$ ). The thoron emanation features were also calculated from the obtained results (2.9 to $21.2 \%$ with an average of $8.6 \%)$. The thoron exhalation and emanation properties were compared with the radon exhalation and emanation features determined in a previous study. It was found that there was no correlation between the radon and thoron emanation features, according to the obtained data. This can be explained by the different Ra-224 and Ra-226 distributions in the soil grains. As a result, the thoron emanation factor cannot be predicted from radon emanation and vice versa.
\end{abstract}

Key words: emanation $\bullet$ exhalation $\bullet$ gamma spectrometry $\bullet$ PIC detector $\bullet$ soil $\bullet$ thorium $\bullet$ thoron

Z. Sas, E. Kocsis, J. Somlai, T. Kovács ${ }^{\bowtie}$ Institute of Radiochemistry and Radioecology, University of Pannonia,

Egyetem u. 10, H-8200, Veszprém, Hungary, Tel.: +36 88624 789, Fax: +36 88624 178,

E-mail: kt@almos.uni-pannon.hu

\section{J. Jónás}

Institute of Radiochemistry and Radioecology,

University of Pannonia,

Egyetem u. 10, H-8200, Veszprém, Hungary and Social Organization for Radioecological Cleanliness, József Attila u. 7/a., H-8200, Veszprém, Hungary

J. Vaupotic

Radon Centre,

Department of Environmental Sciences,

Jožef Stefan Institute,

Jamova 39, 1000 Ljubljana, Slovenia

Received: 8 January 2016

Accepted: 24 March 2016

\section{Introduction}

The radon isotopes ( $\mathrm{Rn}-222$ and $\mathrm{Rn}-220)$ and their progenies are responsible for more than $50 \%$ of natural radiation dose and the second leading factor in the case of the development of lung cancer after smoking [1]. Rn-222 (radon) and Rn-220 (thoron) are generated in crustal materials from their natural Ra-226 (U-238 decay series) and Ra-224 (Th-232 decay series) content, respectively. As a result of the alpha decay of the mother elements, the newly formed radon and thoron atoms recoil (average recoil energy on formation: radon $=86 \mathrm{keV}$, thoron $=103 \mathrm{keV}$ ) [2], which makes their escape from the matrix possible. This phenomenon is called radon or thoron emanation depending on the parent isotope. The emanation is defined as the radon or thoron atoms formed by the decay of their mother element that escapes from the grains (mainly because of recoil) into the interstitial space between the grains [3]. The ratio between the emanated and total radon and thoron originating from the grains is known as the radon/thoron emanation factor. This phenomenon greatly depends on several factors, such as grain size distribution and pore size distribution, porosity features, inhomogeneity of radium isotopes in the grains, moisture content, and so on. Only the emanated radon and thoron can exhale from the pore spaces. Owing to their half-lives (3.82 days 
for radon and $55.6 \mathrm{~s}$ for thoron), radon and thoron atoms located within the solid grains can diffuse towards the surface [3].

The transportation of radon gas can only occur in pore spaces; the rock matrix itself is excluded from this process. The movement of radon and thoron in any porous material can be described by the following physical processes:

- diffusion of radon gas induced by the concentration gradient,

- movement of pore-filling - fluid or gaseous - material (filtration),

- radioactive decay of radon or thoron,

- continuous generation of radon and thoron from Ra-226 and Ra-224, respectively.

The radon/thoron exhalation greatly depends on the characteristics of the sample. The main factors that can have an effect on exhalation are the following:

- Ra-226 and Ra-224 activity concentrations $\left[\mathrm{Bq} \cdot \mathrm{kg}^{-1}\right]$,

- bulk density of the matrix $\left[\mathrm{kg} \cdot \mathrm{m}^{-3}\right]$,

- emanation factor (dimensionless),

- diffusion coefficient $\left[\mathrm{m}^{2} \cdot \mathrm{s}^{-1}\right]$,

- thickness of the matrix $[\mathrm{m}]$.

The survey of radon exhalation from various media, such as building materials, soils, and by-products, is common [4-13], while thoron is of less interest owing to its complicated measurement technique and presumably, its less significant dose contribution. Owing to significantly lower diffusion length of thoron than radon, in general, thoron could be an indoor problem only when the source is present in the building material. However, the thoron indoor concentration is normally lower than that for radon, but the $\mathrm{Pb}-212$ progeny of thoron with a half-life of $10.6 \mathrm{~h}$ can accumulate to significant levels in breathable air, which highlights its inhalation risk [1]. This is why exposure to thoron and its progenies can be comparable to or even higher than to radon and its progenies. According to some recent surveys, it has been found that elevated thoron concentrations can be observed in some regions of elevated radiological risk [2, 14-20]. In order to measure radon/thoron exhalation, the accumulation chamber technique can be used. The increase in radon or thoron concentrations in the chamber as a function of time is proportional to the exhalation power. In numerous cases, thoron has a disturbing effect in the case of radon measurements. Several types of radon monitors containing semiconductors or pulse-ionization chamber (PIC) detectors are commercially available. In spite of the numerous advantages of PIC detectors, such as AlphaGUARD (commonly used), the discrimination between radon and thoron has not been solved [21]. In the case of the accumulation technique, the disturbing effect and the decay correction factor of thoron can be determined precisely as a result of the intercomparison with radon/thoron discriminative detectors (e.g., RAD7), which make the measurement of thoron exhalation possible.

In this study, an AlphaGUARD 2000 professional radon monitor with a PIC detector using an accumulation chamber technique was optimized to measure the thoron exhalation of Slovenian soil samples. HPGe gamma spectrometry was applied to determine the Th-232 activity concentration of the samples to calculate the thoron emanation factor of the samples. The surveyed samples were investigated previously to determine the radon emanation factor and those results were compared with the recently obtained thoron exhalation and emanation factor results [3].

The objectives of the study are:

1. Determination of thoron massic exhalation of Slovenian soil samples using accumulation chamber techniques combined with a radon monitor.

2. Determination of their Th-232 content using HPGe gamma spectrometry.

3. Comparison of radon and thoron emanation and exhalation features.

\section{Experimental programme - description}

\section{Materials and sample preparation}

In the previous study published by Kardos et al. [3], 58 soil samples uniformly distributed over the entirety of Slovenia were investigated about the radon emanation point of view. In current studies, 51 samples of the previously investigated 58 samples were still available for measurement. The soil samples were heated to a constant mass at a temperature of $105^{\circ} \mathrm{C}$ to remove all moisture content, grinded under $0.63 \mathrm{~mm}$, and homogenized. The samples were put into air-tight aluminium Marinelli vessels, weighed, and enclosed. After gamma spectrometry measurements were conducted, the powdered soil samples were enclosed hermetically to avoid the moistening until thoron exhalation measurements were carried out, since the moisture content has a great effect on the emanation coefficient $[5,22]$.

\section{Determination of radionuclide content by gamma spectrometry}

To obtain the radionuclide content, a (HPGe) semiconductor detector (ORTEC GMX40-76, with an efficiency of $40 \%$ and energy resolution of $1.95 \mathrm{keV}$ at $1332.5 \mathrm{keV}$ ) was used. The data and spectra were recorded using an ORTEC DSPEC LF 8196 MCA. The Th-232 activity concentration was measured using the $911 \mathrm{keV}$ gamma ray of Ac-228 and Tl-208 using the $2614 \mathrm{keV}$ gamma ray. To calculate the activity concentration, the obtained spectra were compared with a certificated IAEA reference material (IAEA-327 soil sample). The sample measuring time varied between $60000 \mathrm{~s}$ and $80000 \mathrm{~s}$.

\section{Determination of massic exhalation and emanation}

Exhalation is the radon/thoron activity that diffuses per unit of time from a material into the air surrounding the material, in $\left[\mathrm{Bq} \cdot \mathrm{s}^{-1}\right]$ defined by the Nether- 
lands Standardization Institute [9]. The exhalation can be related to either the surface area of the exhaling surfaces (the areic radon flux in $\left[\mathrm{Bq} \cdot \mathrm{m}^{-2} \cdot \mathrm{s}^{-1}\right]$ ) or the mass of the samples (massic radon exhalation in $\left.\left[\mathrm{Bq} \cdot \mathrm{kg}^{-1} \cdot \mathrm{s}^{-1}\right]\right)$. If the thickness of the samples is significantly smaller against the diffusion length of radon, the massic exhalation can be determined. In this case, all the emanated radon/thoron exhales from the containing matrix and the massic radon/ thoron exhalation can be determined [6]. The relatively short half-life of thoron makes the sampling process cardinal. Until the measurable air reaches, the effective detector space a significant amount of thoron could decay depending on the inhomogeneity of thoron in the measurement system, the flow rate of the airflow, the size of the measurement system, and even the length of the tubing, which all have a significant effect on the measured results. This is the reason why the thoron decay correction factor has to be determined for every measurement set up in order to ensure accurate measurement results. The decay correction factor of the applied measurement kit and sampling method was determined using a RAD7 (Durridge Company, USA) radon/thoron monitor and thorium (IV) nitrate powder. The RAD7 detector was used only for the determination of decay correction factors. After the intercomparison with AlphaGUARD PRO type radon monitor and determination of appropriate measurement conditions, the RAD7 detector was no longer necessary. The thoron exhalation was measured with the help of an accumulation chamber technique [12, 23] (Fig. 1). To ensure a low sample thickness against the diffusion length of thoron, a 3-4 $\mathrm{mm}$ of a powdered layer was applied using a multi-tray sample holder system inside the accumulation chamber (Fig. 1). A homogenous thoron concentration was ensured with intensive air mixing performed by a $12 \mathrm{~V}$ DC fan. The measurement conditions were tested by powdered thorium nitrate.

The soil samples were put into the air-tight accumulation chamber. Nitrogen gas was used to aerate the accumulation kit to ensure a radon- and thoron-free initial accumulation condition. To measure the airflow, a professional AlphaGUARD

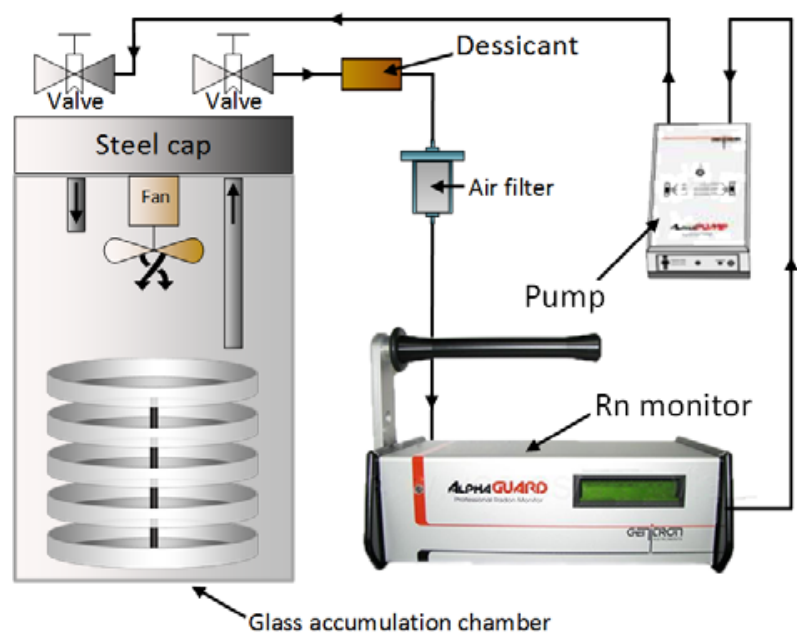

Fig. 1. Scheme of applied measurement kit with a multi-tray sample holder.

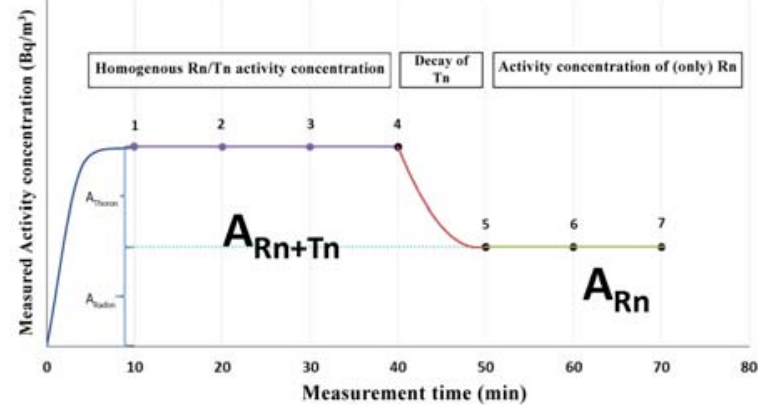

Fig. 2. Flowchart of sampling method.

PRO type radon monitor was applied in the 10 MIN FLOW mode.

Altogether, the sampling process (Fig. 2) took $70 \mathrm{~min}$. After enclosure and aeration, the airflow with $1.0 \mathrm{dm}^{3} \cdot \mathrm{h}^{-1}$ was started and within $10 \mathrm{~min}$, the thoron reached a state of equilibrium inside the measurement kit. After a homogenous thoron concentration was ensured in the airflow (first $10 \mathrm{~min}$ of the circulation), the instrument measured the radon + thoron content of the airflow over $30 \mathrm{~min}$. In order to determine the only radon content of the examined air - which cannot be distinguished by the PIC type AlphaGUARD radon monitor - the circulation of the airflow was stopped and the air in the detector chamber stuck in the radon monitor. During the following period $(10 \mathrm{~min})$, the thoron decayed and only the radon remained in the detector chamber owing to its half-life of 3.82 days. The radon content was measured over $30 \mathrm{~min}$. The thoron concentration was obtained from the difference between the obtained results of thoron + radon and only the radon-containing period, as it is presented in Fig. 2.

The calculation of thoron exhalation was adopted from the calculation method of radon exhalation in case of enclosed sample method was published by Petropoulos et al. [24]. The exhalation phenomena for thoron is similar. Only the half-life is different, which can be taken into consideration with the replacement of decay constant for thoron's.

The thoron exhalation under the equilibrium condition was calculated with following equation:

$$
E_{\mathrm{Tn}}=\frac{A_{\text {eq_thoron }} \cdot F_{C}}{F_{A} \cdot m \cdot t_{\text {eq }}}
$$

where: $E_{\mathrm{Tn}}-$ massic thoron exhalation $\left[\mathrm{mBq} \cdot \mathrm{kg}^{-1} \cdot \mathrm{s}^{-1}\right]$; $A_{\text {eq_thoron }}$ - equilibrium thoron activity $[\mathrm{Bq}] ; F_{C}-$ decay correction factor of thoron in the airflow (dimensionless); $F_{A}$ - decay correction factor of thoron under secular equilibrium conditions (dimensionless); $m$-mass of the sample $[\mathrm{kg}] ; t_{\mathrm{eq}}-$ secular equilibrium time (389 s).

The emanation factor of soil samples was obtained with following equation:

$$
\varepsilon=\frac{A_{\text {eq thoron }}}{A_{\text {Th-232 }}}
$$

where: $\varepsilon$ - emanation factor; $A_{\text {eq thoron }}$ - equilibrium thoron activity $[\mathrm{Bq}] ; A_{\text {Th-232 }}-$ Th-232 activity $\left(A_{\text {Th-232 }}\right)$ of belonging samples $[\mathrm{Bq}]$. 

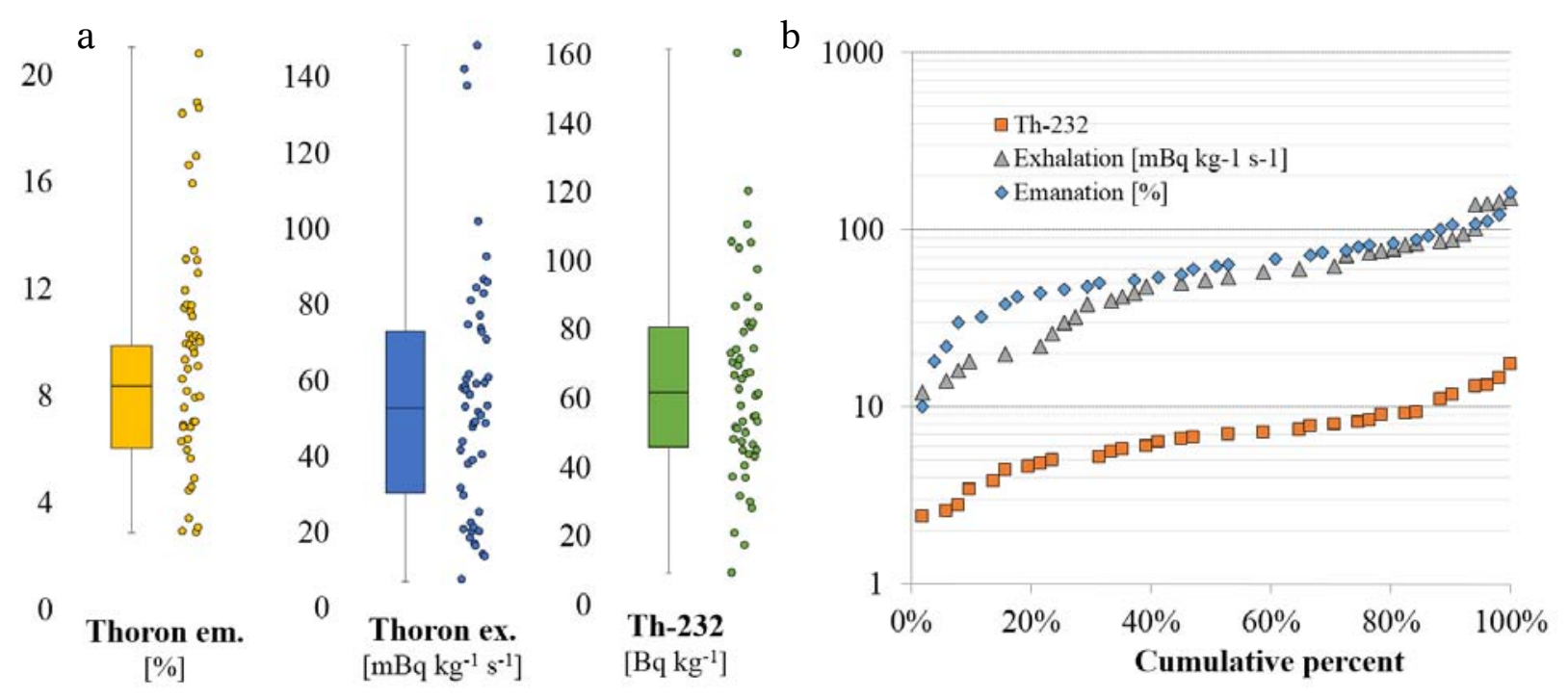

Fig. 3. (a) Box and whisker diagram. (b) Cumulative distribution of measured parameters.

\section{Results and discussion}

Th-232 content, thoron exhalation, and emanation factor of soil samples

The Th-232 activity concentration and the thoron exhalation and emanation factors of 51 investigated Slovenian soil samples are illustrated in the box and whisker diagrams (Fig. 3a). The Th-232 content of the soil samples ranged between $9.3 \pm 0.3$ and $161.7 \pm$ $5.7 \mathrm{~Bq} \cdot \mathrm{kg}^{-1}$ (average: $64.6 \pm 2.3 \mathrm{~Bq} \cdot \mathrm{kg}^{-1}$, median: 61.8 $\pm 2.2 \mathrm{~Bq} \cdot \mathrm{kg}^{-1}$ ), and the thoron exhalation between $6.9 \pm 1.3$ and $149 \pm 10.8 \mathrm{mBq} \cdot \mathrm{kg}^{-1} \cdot \mathrm{s}^{-1}$ (average: 55.2 $\pm 6.4 \mathrm{mBq} \cdot \mathrm{kg}^{-1} \cdot \mathrm{s}^{-1}$, median: $\left.52.7 \pm 7.2 \mathrm{mBq} \cdot \mathrm{kg}^{-1} \cdot \mathrm{s}^{-1}\right)$. The emanation factors were calculated from the measurable thoron activities of the samples under equilibrium conditions and the Th-232 content of the samples. The obtained thoron emanation factors varied between $2.9 \pm 0.5$ and $21.1 \pm 0.8 \%$ (average: $8.6 \%$, median: $8.4 \%$ ). All the studied parameters roughly fit a lognormal distribution (Fig. 3b).
Figure 4 presents the correlation between the investigated parameters. The obtained results show that the thoron exhalation of the samples increased as a function of the Th-232 content and the emanation factor as well. As it was expected, no correlation was found between the Th-232 content and the emanation factor. The results clearly proved that the emanation factor is of great importance with regard to exhalation since in spite of the largest Th-232 content, the measured thoron exhalation of the sample was not the greatest among the samples. The matrix of the soil samples has a great effect on emanation and exhalation.

The obtained thoron emanation- and exhalation-related results were compared with radon emanation and exhalation results investigated on the same soil samples previously by Kardos et al. [3]. As a result of the comparison, it was found (Fig. 5a) that there was no correlation between the radon and thoron emanation factors in spite of the relatively similar recoil energies of the decay of their parent elements.
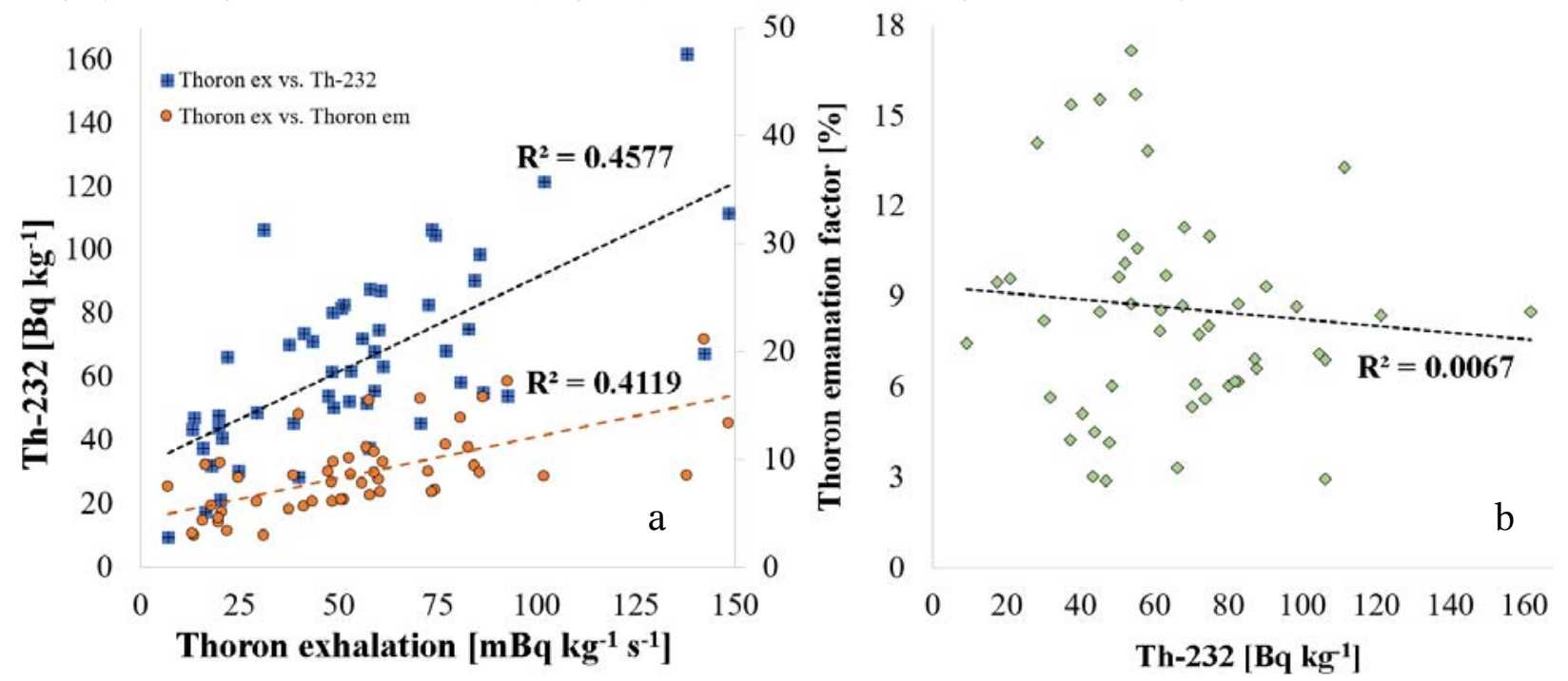

Fig. 4. (a) Thoron exhalation vs. Th-232 content and thoron emanation factor. (b) Th-232 content and thoron emanation factor. 

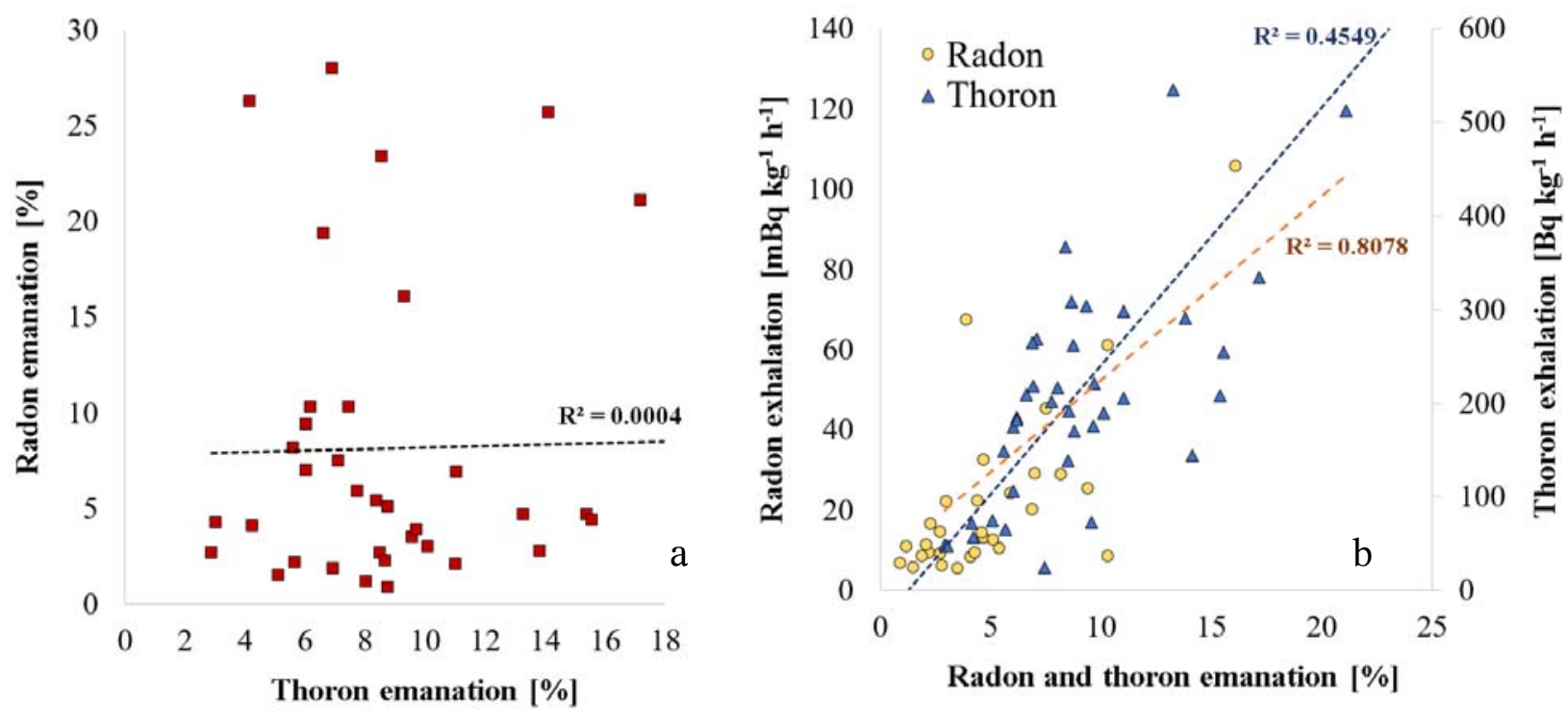

Fig. 5. (a) Radon emanation vs. thoron emanation. (b) Radon exhalation vs. radon emanation and thoron exhalation vs. thoron emanation.

It can be explained by the inhomogeneity of Ra-224 and Ra-226 isotopes in the grains of the soil samples. To investigate the inhomogeneity of Ra-224 and Ra-226 in soil samples, further fine fractionation could prove the assumption. With regard to radon exhalation, a significantly stronger correlation was observed than thoron exhalation (Fig. 5b). Owing to that fact, it can be presumably stated that radon is more dependent on exhalation features than thoron.

\section{Summary}

Altogether, 51 Slovenian soil samples were investigated from a radiological point of view with particular regard to thoron exhalation features. An accumulation chamber technique was applied using a multi-tray sample holder with 3-4 mm depth of powdered sample to ensure low sample thickness against the diffusion length. The massic thoron exhalation results were obtained with the help of an AlphaGUARD radon monitor and predefined thoron decay correction factors. The radon (massic) exhalation ranged between $6.9 \pm 1.3$ and $149 \pm 10.8 \mathrm{mBq} \cdot \mathrm{kg}^{-1} \cdot \mathrm{s}^{-1}$ (average: 55.2 $\pm 6.4 \mathrm{mBq} \cdot \mathrm{kg}^{-1} \cdot \mathrm{s}^{-1}$, median: $\left.52.7 \pm 7.2 \mathrm{mBq} \cdot \mathrm{kg}^{-1} \cdot \mathrm{s}^{-1}\right)$. The emanation factors were obtained from the thoron concentrations under secular equilibrium conditions and the Th-232 activity concentrations $(9.3 \pm 0.3$ and $161.7 \pm 5.7 \mathrm{~Bq} \cdot \mathrm{kg}^{-1}$, average: $64.6 \pm 2.3 \mathrm{~Bq} \cdot \mathrm{kg}^{-1}$, median: $61.8 \pm 2.2 \mathrm{~Bq} \cdot \mathrm{kg}^{-1}$ ) determined by gamma spectrometry. The emanation factors ranged between $2.9 \pm 0.5$ and $21.1 \pm 0.8 \%$ (average: $8.6 \%$, median: $8.4 \%)$. The obtained thoron exhalation and emanation related results were compared with the radon emanation and exhalation features of the same soil samples, which were determined in our previous study. It was found that there was no correlation between the radon and thoron emanation factors. This can be presumably explained by the different distributions of Ra-224 and Ra-226 mother elements in the grains of the soils. Owing to that fact, it can be stated that the thoron emanation factor cannot be predicted from the radon emanation factor. Furthermore, it was found that in the case of radon exhalation, the relationship between it and the emanation factor was greater than with regard to thoron exhalation.

Acknowledgments. The author(s) would like to acknowledge the contribution of the COST Action TU1301; www.norm4building.org and this research was supported by the Hungarian Research Fund [OTKA Nos. K 116506].

\section{References}

1. World Health Organization. (2009). WHO handbook on indoor radon: a public health perspective. Geneva: WHO Press.

2. Meisenberg, O., \& Tschiersch, J. (2012). Specific properties of a model of thoron and its decay products in indoor atmospheres. Nukleonika, 55 (4), 463-469.

3. Kardos, R., Gregoric, A., Jonas, J., Vaupotic, J., Kovacs, T., \& Ishimori, Y. (2015). Dependence of radon emanation of soil on lithology. J. Radioanal. Nucl. Chem., 304, 1321-1327. DOI: 10.1007/s10967-015-3954-3.

4. Kovler, K. (2011). Legislative aspects of radiation hazards from both gamma emitters and radon exhalation of concrete containing coal fly ash. Constr. Build. Mater., 25(8), 3404-3409. DOI: 10.1016/j. conbuildmat.2011.03.031.

5. Sas, Z., Somlai, J., Jonas, J., Szeiler, G., Kovacs, T., Gyongyosi, Cs., \& Sydo, T. (2013). Radiological survey of Hungarian clays; radon emanation and exhalation influential effect of sample and internal structure conditions. Rom. J. Phys., 58, 243-250.

6. Sas, Z., Somlai, J., Szeiler, G., \& Kovacs, T. (2015). Usability of clay mixed red mud in Hungarian building material production industry. J. Radioanal. Nucl. Chem., 306, 271-275. DOI: 10.1007/s10967-0153966-z.

7. Shiroma, Y., Hosoda, M., Ishikawa, T., Sahoo, S. K., Tokonami, S., \& Furukawa, M. (2015). Estimation of radon emanation coefficient for representative soils 
in Okinawa, Japan. Radiat. Prot. Dosim., 167(1/3), 147-150. DOI: $10.1093 / \mathrm{rpd} / \mathrm{ncv} 233$.

8. Somlai, J., Horvath, M., Kanyar, B., Lendvai, Z., \& Nemeth, Cs. (1999). Radiation hazard of coal-slags as building material in Tatabanya town (Hungary). Health Phys., 75(6), 648-651. DOI: 10.1097/00004032-199812000-00010.

9. Netherlands Standardization Institute. (2001). Dutch Standard: Radioactivity measurement. Determination method of the rate of the radon exhalation of dense building materials. NEN 5699:2001. Netherland, Postbus.

10. Tokonami, S. (2005). Summary of dosimetry (radon and thoron) studies. Int. Congress Series, 1276(2), 151-154. DOI: 10.1016/j.ics.2004.09.056.

11. Zunic, Z. S., Fujimoto, K., Yarmoshenko, I. V., Birovljev, A., Celikovic, I., Ujic, P., Simopoulos, S. E., Olko, P., Budzanowski, M., McLaughlin, J. P., \& Waligorski, M. P. R. (2004). Field investigations on radon, thoron and penetrating environmental radiation in selected regions of the western Balkan countries. In 11th International Congress of International Radiation Protection Agency, IRPA11, 23-28 May 2004 (pp. 23-28). Madrid, Spain.

12. Ishimori, Y., Lange, K., Martin, P., Mayya, Y. S., \& Phaneuf, M. (2013). Measurement and calculation of radon releases from NORM residues. Vienna: IAEA. (Technical Reports Series no. 474).

13. Somlai, J., Jobbagy, V., Nemeth, Cs., Gorjanacz, Z., Kavasi, N., \& Kovacs, T. (2006). Radiation dose from coal slag used as building material in the Transdanubian region of Hungary. Radiat. Prot. Dosim., 118(1), 82-87. DOI: $10.1093 / \mathrm{rpd} / \mathrm{nci32}$.

14. Doi, M., Kobayashi, S., \& Fujimoto, K. (1992). A passive measurement technique for characterization of high-risk houses in Japan due to enhanced levels of indoor radon and thoron concentrations. Radiat. Prot. Dosim., 45(1/4), 425-430.

15. Kudo, H., Tokonami, S., Omori, Y., Ishikawa, T., Iwaoka, K., Sahoo, S. K., Akata, N., Hosoda, M., Wanabongse, P., Pornnumpa, C., Sun, Q., Li, X., \& Akiba, S. (2015). Comparative dosimetry for radon and thoron in high background radiation areas in China. Radiat. Prot. Dosim., 167(1/3), 155-159. DOI: $10.1093 / \mathrm{rpd} / \mathrm{ncv} 235$.
16. Mjones, L., Falk, R., Mellander, H., \& Nyblom, L. (1992). Measurements of thoron and thoron progeny indoors in Sweden. Radiat. Prot. Dosim., 45(1/4), 249-352.

17. Milic, G., Jakupi, B., Tokonami, S., Trajkovic, R., Ishikawa, T., Celikovic, I., Ujic, P., Cuknic, O., Yarmoshenko, I., Kosanovic, K., Adrovic, F., Sahoo, S. K., Veselinovic, N., \& Zunic, Z. S. (2010). The concentrations and exposure doses of radon and thoron in residences of the rural areas of Kosovo and Metohija. Radiat. Meas. 45(1), 118-121. DOI: 10.1016/j.radmeas.2009.10.052.

18. Nuccetelli, C., \& Bochicchio, F. (1998). The thoron issue: monitoring activities, measuring techniques and dose conversion factors. Radiat. Prot. Dosim., 78(1), 59-64. DOI: 10.1093/oxfordjournals.rpd.a032334.

19. Szabo, Zs., Jordan, Gy., Szabo, Cs., Horvath, A., Holm, O., Kocsy, G., Csige, I., Szabo, P., \& Homoki, Zs. (2014). Radon and thoron levels, their spatial and seasonal variations in adobe dwellings - a case study at the great Hungarian plain. Isot. Environ. Health Stud. 50(2), 211-225. DOI: 10.1080/10256016.2014.862533.

20. Zak, A., Biernacka, M., \& Mamont-Ciesla, K. (1993). Investigation of radon and thoron from building walls. Nukleonika, 38(4), 39-50.

21. Kochowska, E., Kozak, K., Kozlowska, B., Mazur, J., \& Dorda, J. (2009). Test measurements of thoron concentration using two ionization chambers AlphaGUARD vs. radon monitor RAD7. Nukleonika, 54(3), 189-192.

22. Sun, H., \& Furbish, D. J. (1995). Moisture content effect on radon emanation in porous media. J. Contam. Hydrol., 18(3), 239-255. DOI: 10.1016/01697722(95)00002-D.

23. Csige, I., Szabo, Zs., \& Szabo, Cs. (2013). Experimental technique to measure thoron generation rate of building material samples using RAD7 detector. Radiat. Meas., 59, 201-204. DOI: 10.1016/j.radmeas.2013.07.003.

24. Petropoulos, N. P., Anagnostakis, M. J., \& Simopoulos, S. E. (2001). Building materials radon exhalation rate: ERRICCA intercomparison exercise results Sci. Tot. Environ., 272(1/3), 109-118. DOI: 10.1016/ S0048-9697(01)00674-X. 